\title{
Lymphocyte subset ratios and factor VIII usage in haemophilia
}

\author{
A C BEDDALL, K AL-RUBEI, M D WILliaMS, AND F G H HILL \\ Department of Haematology, Children's Hospital, Birmimgham
}

SUMMARY Type and quantity of replacement treatment, together with haematological and immunological parameters were determined in 37 boys with severe haemophilia A and 41 children with other bleeding disorders. The quantity of factor VIII concentrate given to boys with severe haemophilia A (mean U/year) showed a significant inverse correlation with total white cell counts, lymphocyte counts, platelet counts, and the ratio of monoclonal antibody defined $\mathrm{T}$ lymphocyte subsets, T4 and T8 (T4:T8). Of the boys with severe haemophilia A, 49\% had inversed T4:T8 ratios and $24 \%$ had thrombocytopenia. Treatment with high dose factor VIII concentrate (more than $25000 \mathrm{U} /$ year) was associated with low platelet counts, low lymphocyte counts, low T4:T8 ratios, and hypergammaglobulinaemia. In addition, six patients with severe haemophilia A and factor VIII inhibitors had inversed T4:T8 ratios. Patients treated exclusively with cryoprecipitate or prothrombin complex concentrates had normal T4:T8 ratios and platelet counts. The severity of the haematological and immunological abnormalities observed seems to be associated with high usage of factor VIII concentrates. Similar abnormalities have been described in patients with the acquired immune deficiency syndrome (AIDS). Prospective study of haemophiliacs is required to assess long term sequelae of factor concentrate usage, including the possible development of AIDS.

Immunological abnormalities have recently been found in otherwise healthy patients with severe haemophilia $\mathrm{A},{ }^{1-8}$ and include lymphopenia, a relative and absolute reduction of $\mathrm{T}$ helper lymphocytes, and a relative increase of $T$ suppressor lymphocytes giving an inversed $T$ helper: $T$ suppressor ratio (T4:T8). Lyophilised factor VIII concentrates have been implicated as the cause of these abnormalities rather than cryoprecipitate, ${ }^{23}$ although immunological studies have not always been normal in haemophiliacs treated with cryoprecipitate. ${ }^{9} 11$

The quantity of administered factor VIII concentrates has not seemed to correlate with changes in T cell subpopulations, ${ }^{2} 3612$ although two reports have related low T4:T8 ratios with higher exposure to factor VIII concentrate. ${ }^{1314}$ Patients treated with prothrombin complex concentrates have generally had similar immunological findings to controls, ${ }^{6913}$ although this has not been a consistent finding. ${ }^{14}$

Thrombocytopenia, of an immune type in some cases, ${ }^{15}$ has been reported in patients with haemophilia A. ${ }^{6} 16{ }^{17}$ A relation, however, between transfused factor VIII concentrate and thrombocytopenia has not been established.
Haemophilic boys and adolescents have been reported with immunological abnormalities similar to those described in adult haemophiliacs and patients with the acquired immune deficiency syndrome (AIDS). ${ }^{4}$ Prospective longitudinal study of haemophiliacs is clearly needed to assess both the importance of these abnormalities and the degree of risk of developing AIDS. We have initiated such a study of haemophilic boys and children with other bleeding disorders. The type and quantity of blood products have been evaluated in relation to immunological and haematological abnormalities.

\section{Patients and methods}

Patients. All patients studied attend the Haemophilia Unit, Children's Hospital, Birmingham, and were healthy at the time of the study.

Thirty seven boys (mean age $8 \cdot 1$ years) had severe haemophilia A (presenting factor VIII:C less than $2 \%$ ) and all had received both commercial (Armour Intermediate Purity Factor VIII) and NHS factor VIII concentrates. Among these patients there were four high and two low responder 
inhibitor patients. Three of the high responders had also at times received Factor Eight Inhibitor Bypassing Activity product (FEIBA, Immuno, Austria) when treatment with factor .VIII concentrate had failed. Complete treatment records are available for these children. Mean factor VIII consumption by severe haemophiliacs including the inhibitor patients was 23000 U/year. For the purpose of analysis, however, we have divided patients with severe haemophilia A into high treatment (mean treatment greater than $25000 \mathrm{U} /$ year), and low treatment (less than 25000 U/year) groups.

Seventeen boys (mean age 9.7 years) with mild/ moderate haemophilia A (presenting factor VIII:C greater than $2 \%$ ) were studied, 11 of whom had received both factor VIII concentrate and cryoprecipitate, and six cryoprecipitate only. One of these boys had become a high responder inhibitor patient and this made his haemophilia more severe. He required frequent treatment (mean yearly usage of $30000 \mathrm{U}$ factor VIII) like most of the other inhibitor and severe haemophiliac patients. Treatment of inhibitor patients was mainly with high doses of factor VIII concentrate.

Nine patients with von Willebrand's disease and six patients with combined factors $\mathrm{V}$ and VIII deficiency (mean age 11 years) had received only cryoprecipitate and were considered as a separate patient/treatment group. Some had received treatment infrequently.

Seven boys with severe haemophilia B (factor IX less than $2 \%$ ) and two boys with severe factor $X$ deficiency (factor $\mathrm{X}$ less than $2 \%$ ) were studied (mean age 7.5 years). All had been treated with NHS prothrombin complex concentrates (mean consumption $18000 \mathrm{U} /$ year), and were considered as an additional patient/treatment group. One of the boys with haemophilia $B$ is a high responder inhibitor patient.
Controls. Twenty five children without haemostatic problems formed the control group. All were well at the time, and apart from six having elective surgery, the others were normal children being investigated for small stature which had been shown to be constitutional, that is they are short, otherwise normal children.

Statistical analysis. Patient and control groups were analysed statistically using the Mann-Whitney test, Spearman's rank correlation coefficient, and $\chi^{2}$ where appropriate.

Methods. Total white cell counts were determined with a Coulter $S$ counter on venous blood anticoagulated with ethylenediamine tetra-acetic acid, and differential white cell counts were done on blood films stained with Wright's stain. Platelet counts were determined using a TOA platelet counter (PL100). Automated immunoturbidimetric determination of immunoglobulins by centrifugal analysis was performed. ${ }^{18}$ Liver function tests were performed by standard biochemical methods. Mononuclear cells were isolated on 'Ficoll-Hypaque' and $T$ lymphocyte subsets defined using monoclonal antibodies T4 and T8 by an indirect immunofluorecence, according to the manufacturer's instructions (Coulter Electronics). Helper lymphocytes would be included in those identified by $\mathrm{T} 4$ and suppressor lymphocytes with those identified by T8. Results were finally expressed as T4:T8 ratios.

\section{Results}

Values for total white cell, lymphocyte, and platelet counts, and T4:T8 ratios for each patient group are shown in the Table. Boys with severe haemophilia A in the higher treatment group had significantly lower total white cell counts $(\mathrm{P}<0 \cdot 02)$, lymphocyte counts

Table White cell, lymphocyte, and platelet counts and T4:T8 ratios in control and patient groups (values expressed as mean (SEM))

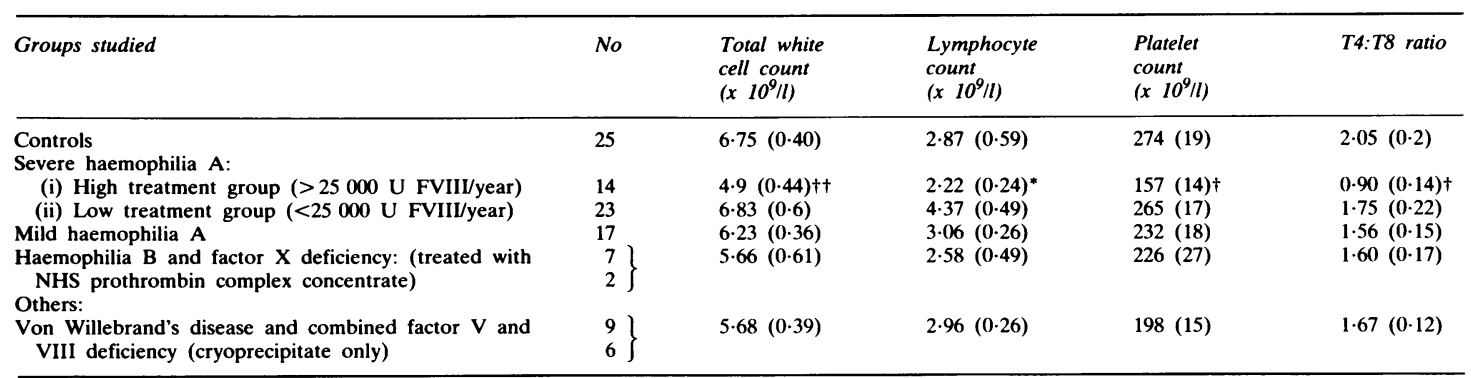

Significantly different from controls ${ }^{*} \mathrm{P}<0.95+\mathrm{P}<0.001 \ddagger \mathrm{P}<0.01$.

FVIII = factor VIII. 
$(\mathrm{P}<0.01$; Fig. 1), platelet counts $(\mathrm{P}<0 \cdot 001$; Fig. 2$)$, and T4:T8 ratios $(\mathrm{P}<0.01 ;$ Fig. 3$)$ than those in the lower treatment group. Eleven of the higher treatment group had an inversed T4:T8 ratio, associated with lymphopenia in three, and thrombocytopenia

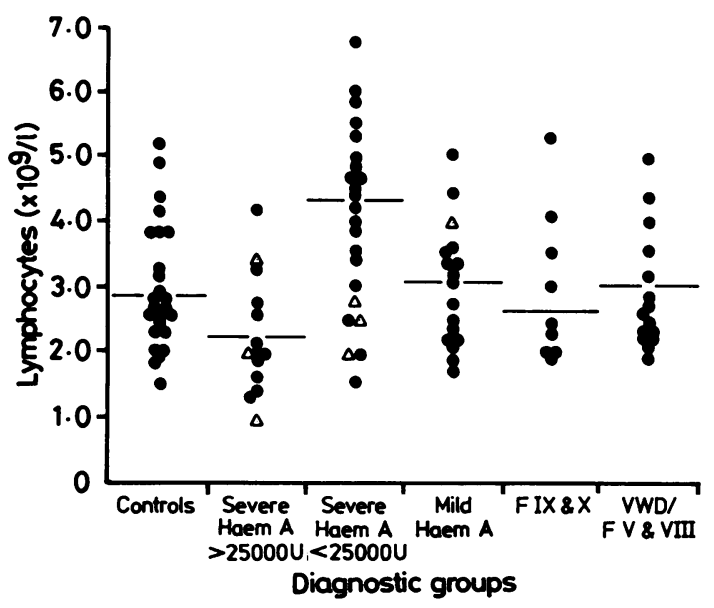

Fig. 1 Lymphocyte counts for subjects in control and diagnostic groups.

Horizontal bar shows mean for each group; $\Delta$ indicates haemophilia $\mathbf{A}$ (Haem A) inhibitor patients.

VWD $=$ von Willebrand's disease; $F=$ factor

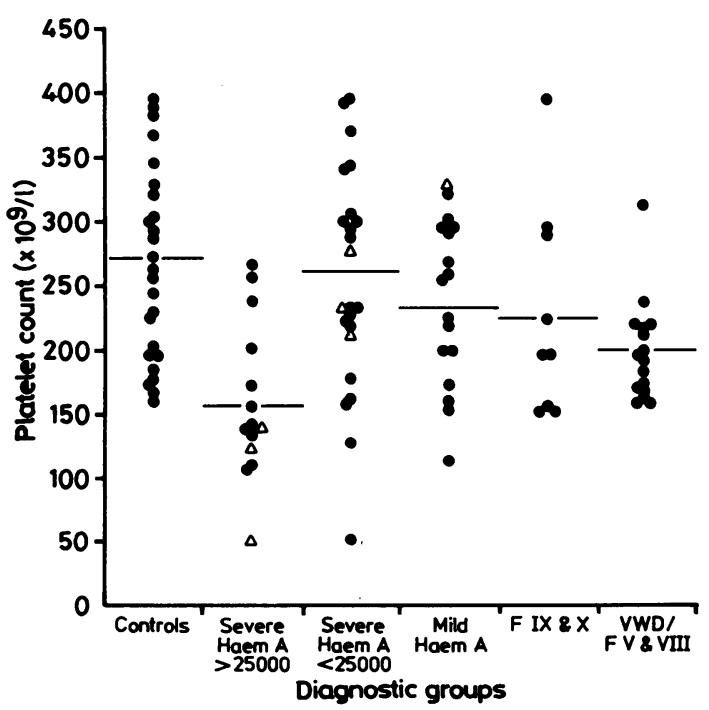

Fig. 2 Platelet counts for subjects in control and diagnostic groups.

Horizontal bar shows mean for each group; $\Delta$ indicates haemophilia $\mathbf{A}$ inhibitor patients.

$\mathrm{VWD}=$ von Willebrand's disease; $F=$ factor

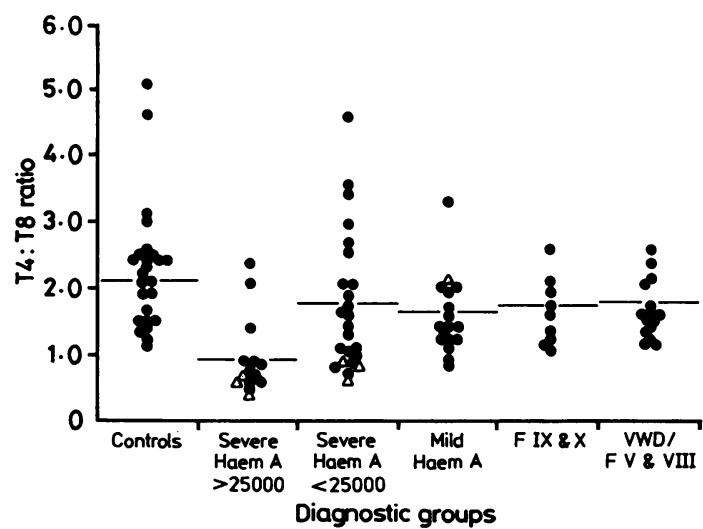

Fig. 3 T4:T8 ratios for subjects in control and diagnostic groups.

Horizontal bar shows mean for each group; $\Delta$ indicates haemophilia $\mathbf{A}$ inhibitor patients.

VWD $=$ von Willebrand's disease; $F=$ factor.

in eight. Despite seven patients in the lower treatment group having inversed T4:T8 ratios, associated with thrombocytopenia in two cases, none had lymphopenia. The lower treatment group, unlike the higher treatment group, did not differ significantly from controls. When each of the following patient groups (lower treatment severe haemophilia $\mathbf{A}$, mild haemophilia $\mathrm{A}$, prothrombin complex treated, and cryoprecipitate treated) were compared with each other, no significant differences were obtained for total white cell, lymphocyte, and platelet counts, and T4:T8 ratios.

The quantity of factor VIII concentrate administered to the patients with severe haemophilia A (expressed as mean yearly usage) as a group, showed a significant inverse correlation with total white cell count $(P<0 \cdot 001)$, lymphocyte counts $(P<0.001$; see Fig. 4), platelet counts $(P<0.001$; see Fig. 5), and T4:T8 ratios $(\mathrm{P}<0 \cdot 01)$. Usage of factor VIII in the year before the study or total units of factor VIII received also correlated significantly with these parameters. Recorded abnormalities did not correlate with age.

Twenty of 37 patients with severe haemophilia A had hypergammaglobulinaemia (when compared with age related reference values). This related to low T4:T8 ratios $\left(\mathrm{P}<0.025 ; \chi^{2}\right)$, low platelet counts $\left(\mathrm{P}<0.025 ; \chi^{2}\right)$, and the higher treatment group $\left(\mathrm{P}<0.01 ; \chi^{2}\right)$. Twenty of 37 patients with severe haemophilia A had raised aspartate and alanine transaminases, which did not relate to higher or lower treatment groups, haematological, or immunological values. 


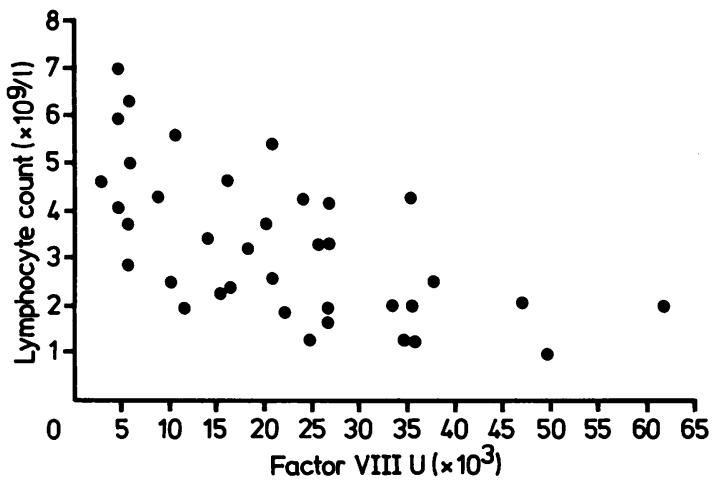

Fig. 4 Scattergram comparing lymphocyte count and mean annual treatment.

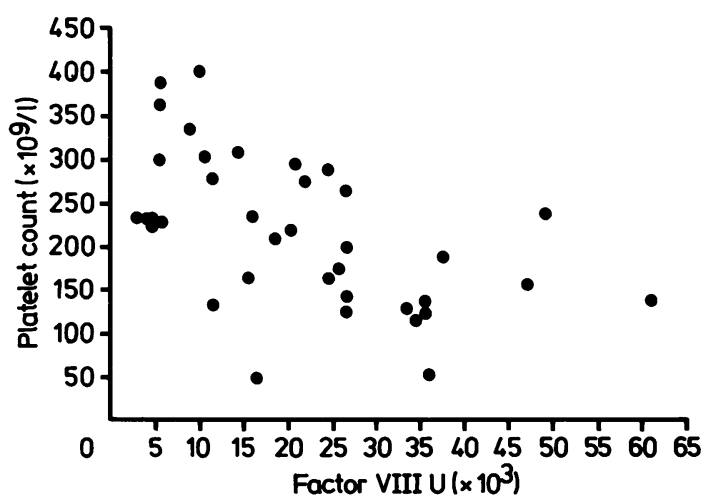

Fig. 5 Scattergram comparing platelet count and mean annual treatment.

Two of 17 patients with mild haemophilia A had inversed T4:T8 ratios, one associated with hypergammaglobulinaemia and thrombocytopenia. Both had recently received factor VIII concentrates. Patients treated exclusively with cryoprecipitate in this group and in other groups (von Willebrand's disease and combined factors V and VIII deficiency) had normal results, apart from two patients with von Willebrand's disease who had only hypergammaglobulinaemia. They had both recently received large quantities of cryoprecipitate.

One patient with haemophilia $\mathrm{B}$, in the group treated with prothrombin complex concentrate, had hypergammaglobulinaemia only. All other haematological and immunological results in this group were normal. Three of nine of these patients had raised transaminases.

Four of five high responders and the two low responder factor VIII inhibitor patients with haemophilia A had inversed T4:T8 ratios. One of these had associated lymphopenia, and two of the high responders and one of the low responders had thrombocytopenia.

One patient with severe haemophilia A, although well, was noted to have lymphadenopathy and splenomegaly at the time of the study. He had an inversed T4:T8 ratio, thrombocytopenia, and hypergammaglobulinaemia.

\section{Discussion}

Haematological and immunological abnormalities have been described in asymptomatic patients with haemophilia A. These include inversed T4:T8 ratios, ${ }^{2}{ }^{3}$ lymphopenia and thrombocytopenia, ${ }^{6}$ and hypergammaglobulinaemia. ${ }^{46}$ Among the boys with severe haemophilia $\mathrm{A}$ in this study, we have found similar findings. In addition, however, we have shown a significant inverse correlation between the quantity of factor VIII concentrate administered and T4:T8 ratios, total white cell, lymphocyte, and platelet counts. Significant differences in these immunological and haematological values were found between the higher treatment group (mean treatment greater than $25000 \mathrm{U} /$ year) and the lower treatment group (less than $25000 \mathrm{U} /$ year). Hypergammaglobulinaemia was significantly associated with low T4:T8 ratios, low platelets, and the higher treatment group. In these patients with severe haemophilia $\mathrm{A}$, increasing abnormalities are associated with increasing usage of factor VIII concentrates. As all these patients had received both NHS and commercial factor VIII, we were unable to ascribe observed abnormalities to type of concentrate.

The pathogenesis of these immunological abnormalities is not known. A transmissible agent, possibly viral, in factor VIII concentrates has been suggested. ${ }^{19}$ The recipients of factor concentrates are known to be at increased risk from a large number of viral infections, including Epstein-Barr virus, cytomegalovirus ${ }^{20}$ hepatitis $B$ and non- $A$ non$\mathrm{B}$ hepatitis, ${ }^{21}$ and serum parvo-like virus. ${ }^{22}$ Alteration of lymphocyte populations is a known sequelae of infection with the first two of these viruses, ${ }^{24} 25$ and serum parvo-like virus has been suggested as a possible cause of the altered $\mathrm{T}$ cell populations seen in haemophiliacs, as it is present in factor VIII concentrate ${ }^{22}$ and animal parvoviruses are known to infect lymphocytes. ${ }^{26}$ Increasing usage of factor VIII concentrate seems to increase the risk of exposure to the lymphadenopathy associated virus or human $\mathrm{T}$ lymphotropic virus type III. ${ }^{23}$ As the former is lymphotropic, it would be expected to have effects on cellular immunity, including lymphocyte popula- 
tions, and may be a relevant factor in the immunological abnormalities we have observed.

Hypergammaglobulinaemia is a recognised finding in some patients with asymptomatic severe haemophilia A. ${ }^{46}$ Noticeable abnormalities of B cell lymphocyte activation and immunoregulation suggestive of viral infection have been described in homosexual men with AIDS, ${ }^{27}$ and similar mechanisms may cause the hypergammaglobulinaemia seen in haemophiliacs. B cell polyclonal activation may be responsible for the increase in circulating immune complexes in homosexual men ${ }^{28}$ some of whom have thrombocytopenia, ${ }^{29}$ and the thrombocytopenia that we and others ${ }^{6} 1517$ have observed in haemophiliacs. The possible relation between disordered immunity and circulating factor VIII inhibitors remains unclear, but all six of our patients with severe haemophilia $A$ and inhibitors had inversed T4:T8 ratios. The pathogenesis of altered T4:T8 ratios in these haemophiliacs may be different or the same as for non-inhibitor patients and requires further study.

Patients treated with prothrombin complex concentrates have generally been reported as having normal immunological studies, ${ }^{13}{ }^{16}$ and our patients treated with NHS factor IX concentrates (haemophilia B and factor X deficiency) have normal T4:T8 ratios, lymphocyte counts, and platelet counts. As prothrombin complex concentrates are made from cryoprecipitate depleted plasma (and the cryoprecipitate used for factor VIII concentrates), it is difficult to explain all of the observed immunological differences between patients with severe haemophilia A and those with haemophilia B purely by the transmission of an infectious agent, unless it is selectively removed in the cryoprecipitate, or is inactivated during the subsequent preparation of the prothrombin concentrate.

Some patients, however, treated with prothrombin complex concentrates have been shown to have abnormal T4:T8 ratios, ${ }^{8914}$ and the finding that small numbers of patients with haemophilia B treated with factor IX concentrates were negative for lymphadenopathy associated virus antibody (and had normal cellular immunity) needs clarification. ${ }^{23}$

It has also been suggested that repeated antigenic challenge by factor VIII concentrate may cause the observed immunological abnormalities. ${ }^{30}$ Differences in the fractionation procedures may lead to immunochemical differences between factor VIII and prothrombin complex concentrates, ${ }^{13}$ and differences in the concentration of the HLA related protein $B_{2}$ microglobulin have been implicated. ${ }^{31}$

Whether the immunological and haematological changes seen in asymptomatic haemophiliacs are secondary to a transmissible agent, repeated anti- genic exposure, or a combination of mechanisms remains unclear. The importance of these changes is as yet unknown. Repeated prospective evaluation may clarify if progression to more severe immunological deficiency states and illness, as seen in homosexuals, ${ }^{32} 33$ will occur in haemophiliacs receiving factor concentrates, as a few deaths presumed to be due to AIDS have been recorded in patients with haemophilia A. ${ }^{34}$ The regular documentation of haematological parameters may also be of relevance to treatment failure as bleeding may arise not from factor VIII deficiency, but from the thrombocytopenia.

We thank Marion Gregory, Haemophilia Sister, for her assistance with venepunctures; the Biochemistry Department, Children's Hospital, Birmingham for performing immunoglobulin analyses, and Mrs P Mann for typing the manuscript. Dr K Al-Rubei and Dr M D Williams are in receipt of Armour Research Fellowships.

\section{References}

1 Jones P, Proctor S, Dickinson A, George S. Altered immunology in haemophilia. Lancet 1983;i: 120 .

2 Ledermann MM, Ratnoff OD, Scillian JJ, Jones PK, Schacter B. Impaired cell-mediated immunity in patients with classic hemophilia. N Engl J Med 1983;308:79-83.

${ }^{3}$ Menitove JE, Aster RH, Casper JT, et al. T-lymphocyte subpopulations in patients with classic hemophilia treated with cryoprecipitate and lyophilised concentrates. $N$ Engl J Med 1983;308:83-6.

${ }^{4}$ Luban NLC, Kelleher JF. Altered distribution of T-lymphocyte subpopulations in children and adolescents with haemophilia. Lancet 1983;i:503-5.

${ }^{5}$ Weintraub P, Ammann AJ, Abrams D, et al. Altered T-cell immunity in hemophiliacs receiving frequent factor VIII concentrate. Blood 1982:Suppl:224a.

6 Lechner K, Niessner H, Bettelheim E, et al. T-cell alterations in hemophiliacs treated with commercial clotting factor concentrates. Thromb Haemost 1983;50:552-6.

${ }^{7}$ Froebel K, Madhok R, Forbes C, Lennie S, Lowe G, Sturrock $R$. Immunological abnormalities in haemophilia: are they caused by American factor VIII concentrate? $\mathrm{Br}$ Med $\mathrm{J}$ 1983;287:1091-3.

8 Carr R, Edmond E, Prescott RJ, et al. Abnormalities of circulating lymphocyte subsets in haemophiliacs in an AIDSfree population. Lancet 1984 ; i:1431-4.

${ }^{9}$ Kessler CM, Schulof RS, Goldstein AL, et al. Abnormal T-lymphocyte subpopulations associated with transfusions of blood-derived products. Lancet 1983;i:991-2.

10 Counts RB, Hansen JA. T-cell subsets in hemophilia. $N$ Engl J Med 1983;308:1292.

11 Rickard KA, Joshua DE, Campbell J, Wearne A, Hodgson J, Kronenberg H. Absence of AIDS in haemophiliacs in Australia treated from an entirely voluntary blood donor system. Lancet 1983;ii:50-1.

12 Saidi P, Kim H, Rashka K. T-cell subsets in hemophilia. N Engl J Med 1983;308:1291.

13 Lee CA, Janossy G, Ashley J, Kernoff PBA. Plasma fractionation methods and T-cell subsets in haemophilia. Lancet 1983;ii:158-159.

${ }^{14}$ de Shazo R, Andes W, Nordberg J, Newton B, Daul C, Bozelka B. An immunologic evaluation of haemophiliac patients and their wives. Ann Intern Med 1983;99:159-164.

15 Ratnoff OD, Menitove JE, Aster RH, Ledermann MM. Coincident classic hemophilia and 'idiopathic' thrombocy- 
topenic purpura in patients under treatment with concentrates of antihemophilic factor (factor VIII). N Engl J Med 1983; 308:439.

16 Suffredini A, Qureshi GD. Concomitant hemophilia and thrombocytopenia. JAMA 1982;247:2497-2498.

17 Bloom AL. Acquired immunodeficiency syndrome and other possible immunological disorders in European haemophiliacs. Lancet 1984;i:1452-5.

18 Boigne JM, Boigne N, Galacteros F, Nalpas B, Phillipon C, Vivien C. Dosage des protéines par immunoprécipitation sur analyseur centrifuge centrichem. Ann Biol Clin (Paris) 1977;35: 237-54.

19 Marx JL. New disease baffles medical community. Science 1982;217:618-21.

20 Enck RE, Betts RF, Brown MR, Miller G. Viral serology (hepatitis B virus, cytomegalovirus, Epstein-Barr virus), and abnormal liver function tests in transfused patients with hereditary haemorrhagic diseases. Transfusion 1979;19:32-8.

21 Craske J, Kirk P, Cohen BJ, Vandervelde EM. Commercial factor VIII-associated hepatitis, 1974-5, in the United Kingdom; a retrospective survey. J Hyg (Lond) 1978;80:327-36.

22 Mortimer PP, Luban NLC, Kelleher JF, Cohen BJ. Transmission of serum parvo-like virus by clotting factor concentrates. Lancet 1983;ii:482-4.

23 Ramsey RB, Palmer EL, McDougal JS, et al. Antibody to lymphadenopathy-associated virus in haemophiliacs with and without AIDS. Lancet 1984;ii:397-8.

24 Carney WP, Rubin RH, Hoffman RA, et al. Analysis of $T$ lymphocyte subsets in cytomegalovirus mononucleosis. $J$ Immunol 1981;126:2114-6.

25 De Walle $\mathbf{M}$, Thielemans C, Van Camp BKG. Characterisation of immunoregulatory $\mathrm{T}$ cells in EBV-induced infectious mononucleosis by monoclonal antibodies. $N$ Engl J Med 1981; 304:460-2.

26 Engers HD, Louis JA, Zubler RH, Hirt B. Inhibition of T cell mediated functions by MVM (i). A parvovirus closely related to minute virus of mice. J Immunol 1981;127:2280-5.

27 Lane HC, Masur H, Edgar LC, Whalen G, Rook $\mathrm{AH}$, Fauci AS. Abnormalities of B-cell activation and immunoregulation in patients with the acquired immunodeficiency syndrome. $N$ Engl J Med 1983;309:453-9.

28 Gottlieb MS, Schroff R, Schanker HM, et al. Pneumocystis carinii pneumonia and mucosal candidiasis in previously healthy homosexual men: evidence of a new acquired cellular immunodeficiency. N Engl J Med 1981;305:1425-31.

${ }^{29}$ Morris L, Distenfield A, Amorosi E, Karpatkin S. Autoimmune thrombocytopenic purpura in homosexual men. Ann Intern Med 1983;96:714-7.

30 Gordon RS. Factor VIII products and disordered immune regulation. Lancet 1983;i:991.

31 Lee C, Kernoff P, Karayiannis P, Waters J, Thomas HC. Abnormal T-lymphocyte subsets in hemophilia: relation to HLA proteins in plasma products. $N$ Engl J Med 1984;309:1058.

32 Kornfield $\mathrm{H}$, Stouwe RAV, Lange $\mathrm{M}$, et al. T-lymphocyte populations in homosexual men. $N$ Engl J Med 1982;307: $729-31$.

33 Centres for Disease Control. Update on Kaposi's sarcoma and opportunistic infections in previously healthy persons-United States. Morbidity and Mortality Weekly Report 1982;31:294, 300-1.

34 Pneumocystis carinii pneumonia among persons with hemophilia A. Morbidity and Mortality Weekly Report 1982;31:365-7.

35 Daly HM, Scott GL. Fatal AIDS in a UK haemophiliac. Lancet 1984;i:44.

Correspondence to Dr F G H Hill, Department of Haematology, Children's Hospital, Ladywood, Birmingham B16 8ET.

Received 30 January 1985.

\section{Commentary}

\section{J S LILLEYMAN}

\section{Children's Hospital, Sheffield}

At the time this paper goes to press the haemophiliac's world is in turmoil. After the widespread introduction of large pool, freeze dried factor VIII concentrate over 10 years ago, replacement treatment in haemophilia has become relatively simple and efficient. Many patients are now on home treatment and there is little doubt that the quality of life for them has improved enormously as a result. But at what price? First there was (and still is) a high incidence of transfusion related chronic hepatitis, ${ }^{12}$ but now that problem, serious enough one might think, has been totally eclipsed by the more dramatic prospect of transfusion transmitted acquired immune deficiency syndrome (AIDS). AIDS was first described in a haemophiliac from the United States in $1982^{3}$ and by the close of 1984 had been noted in a further $51 .^{4}$ At the time of writing, however, only three-all adults-have developed the disease so far in the United Kingdom. The apparently higher incidence in the United States has been supposed to be due to a higher infection rate in the paid donors giving plasma for American factor VIII. If this is so, any difference is likely to be temporary, as much of the American product has been (and still is) used in the United Kingdom despite a large increase in home produced material. Furthermore at least one batch of UK concentrate has proved to be contaminated.

Almost as worrying as the small numbers who have developed the full blown syndrome is the greater prevalence of what might be described as AIDS related phenomena. Some of these are clinically symptomatic disorders with lymphadenopathy, weight loss, fever, or diarrhoea and are generally referred to as AIDS related complex (ARC) syndromes. Others are merely laboratory abnormalities, and include the lymphopenia, T4 lymphocyte reduction, reversed T4:T8 ratios, and thrombocytopenia described here by Beddall $e t$ al. Though not previously shown so clearly, as might be expected these abnormalities seemingly correlate with the degree of exposure to factor VIII concentrate, and over three quarters of the heaviest consumers in this study have been found to have some objective immune disturbance. A worrying statistic indeed as the report deals only with children.

At the same time as studies of non-specific haematological and immunological abnormalities have been carried out, over the last few months it 